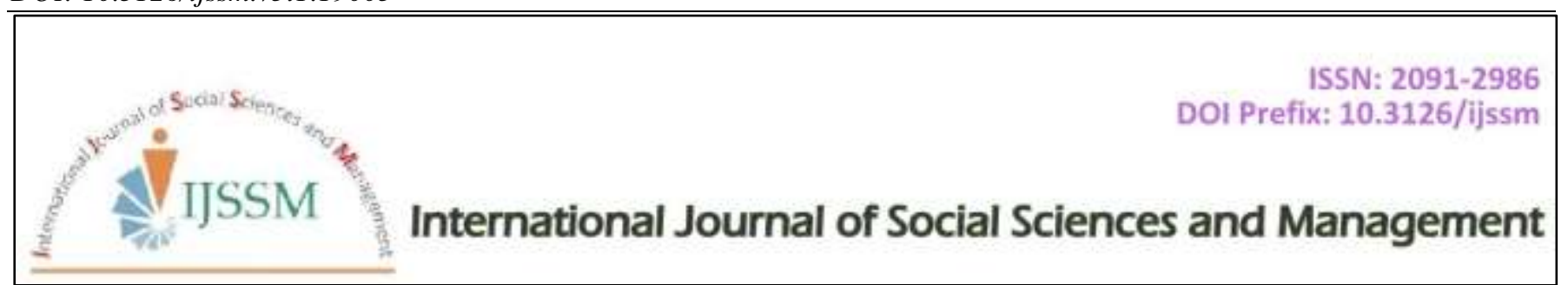

Research Article

\title{
Perceived Brand Globalness- Impact on Women Consumer Response in Indian Fashion and Lifestyle Market
}

\author{
Karan Khurana ${ }^{1 *}$ \\ EiTEX, Bahir Dar University, Ethiopia.
}

\begin{abstract}
This study aims to investigate the effects of perceived brand globalness (PBG) on consumer affective and behavioral responses to brand failures and for how consumer perceives global and local brands and their responses in the event of failure present or absent related to brand performance and brand familiarity, brand presence and prestige, brand equity, product country match, country ethnocentrism.

This research is conducted in regards to women consumers in two cities in North India related to global and local brands with impact of perceived brand globalness to brand failures present or absent scenario based on consumer responses. The research explored into four main factors as dependent variables on which PBG effects are examined and observed in failure present as well as failure absent scenario. This research consists of mainly two studies and two preliminary tests. Study 1 is executed basically to investigate and to test consumer responses towards brand failures of fictitious brands. Study 2 is designed to examine consumer responses to brand failures of established brands.

The study found that PBG effects are more positive on Global brands as compared to the local brands and concluded that consumer is less negative and less impulsive to the global brands when they met failure scenario. The study could not find any significance and examined that customer ethnocentrism does not interrupt with buying behavior. This research was able to test whether global brands are still perceived superior to local brands in the context of Indian consumer and also test whether the effects of PBG on consumer responses to brand failures will be mediated by consumer attribution as blaming or fault accountable in the event of encountering.
\end{abstract}

Keywords: Consumer Behavior; Perceived Brand Globalness (PBG); Brand Failures, Consumer Ethnocentrism (CET); Indian Market.

\section{Introduction}

Globalization has become a development trend of the business world with no doubts. The advantages of building global brands are well recognized in literature. Although the advantages of global brands to brand value are well supported by literature, the effects of global brands in brand failure context are not yet tested. Brand failures as common cases happen to our lives every day. Even big companies cannot guarantee their brands never ever fail their customers. Haig (2005) wrote a book listing up the most

\section{Cite this article as:}

K. Khurana (2018) Int. J. Soc. Sc. Manage. Vol. 5, Issue-1: 18-30. DOI: 10.3126/ijssm.v5i1.19005

$1 *$ Corresponding author

Karan Khurana,

EiTEX, Bahir Dar University, Ethiopia

Email: khurana101karan@gmail.com

Peer reviewed under authority of IJSSM

(C) 2018 International Journal of Social Sciences and Management

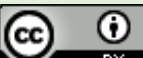

This is an open access article \& it is licensed under a Creative Commons Attribution 4.0 International License (https://creativecommons.org/licenses/by/4.0/)

Full text of this paper can be downloaded online at www.ijssm.org/ \&http://nepjol.info/index.php/IJSSM/issue/archive 
famous 100 brand failures happened to brands such as Dell, Toyota, Sony, McDonald's, Maggi Noodles recently etc. Haig's book described the severe consequences caused by these brand failures. It is really important and necessary to investigate the proper actions to take after brand failures to fix the negative influences.

The concerned study is an attempt to conceptually identify and empirically test the interrelations between perceived brand globalness and its impact on Consumer satisfaction, consumer quality perception, consumers' purchase intention, and word of mouth mediated by consumer attribution and moderated by consumer ethnocentrism. Many literatures test the positive effects of global branding on product evaluations (Keller, 2008; Keller and Aaker, 1992). This research study will focus on the impacts of global branding on consumer responses in brand failure context.

Whether a brand is a global brand or not can be measured from various aspects, for instance, the distributional geographical areas of the brands or the marketing strategies of the brands in different countries. Steenkamp et al. (2003) proposed that the perceived brand globalness (PBG) by consumers would create brand value. They measured whether a brand is global in perspectives of consumers. Their study found that PBG positively influenced the perceived brand quality and brand prestige and then through the two pathways positively influenced the purchase likelihood. It is important to investigate the effects of global brands from the perspectives of consumers, since whether the brand is successfully positioned as a global brand is finally evaluated by the consumers.

\section{Aim of the Research}

- This research will test whether global brands are still perceived superior to local brands in the context of brand failures. The research hypothesizes that $\mathrm{PBG}$ is positively related to consumer behavioral and attitudinal intentions after brand failures happened. The effects of the PBG on consumer responses to brand failures are explained by attribution theory. Folkes and Kotsos (1986) found that the discrepancies in buyer-seller attribution of product failure were due to how commonly they believed the product failure happened. If the failure is believed to happen commonly, the failure will be more likely attributed to the fault of the product. Because of the high-quality perception of global brands, consumers may believe the failure of global brand as not commonly happened cases. Consumers will attribute the failures of global brands happening to them being experienced by few people. Compared with local brands consumers may attribute the failure of the global brands to an accident but not the fault of the global brand. Therefore, in the same failure context, consumer behavioral and attitudinal responses to global brands are less negatively than local brands.

- This research will probe into consumers' considering process when facing to brand failures. Attribution theory will be adopted to explain consumer different reactions to the same failures happen to high PBG and low PBG brands respectively.

- Third, it will test the moderating role of consumer ethnocentrism (CET) on Indian consumers under the context of brand failures. Regarding the moderating effect of CET on the relationship between PBG and consumer responses, there are inconsistent findings in literature.

- Finally, it will explore the facts and shall test whether the effects of PBG on consumer responses to brand failures will be mediated by consumer attribution as blaming or fault accountable in the event of encountering.

\section{Literature Review}

\section{Global Vs Local Brands}

"It's commonly agreed that global brands are the one that consumers can find under the same name in multiple countries with generally similar and centrally coordinated marketing strategies" (Yip, 1995); whereas the local brand are developed for a specific national market. What makes local brands strong is "their being local; these are often more than brands, they are institutions" (Kapferer, 1997).

The advantages of building global brands are well recognized in literature. First of all, the economies of scale save the cost of manufacturing, distribution (Keller, 2008), RandD, and marketing communications (Yip, 1995). Second, global brands are globally accepted and available. The broad scope of the global brands is perceived by consumers as the indications of global brands' expertise and superior to local brands (Kapferer, 1997; Keller, 2008; Shocker et al., 1994). Third, the consistency of brand image and marketing strategies of global brands allow less time consuming in local modification and better control of the quality (Keller, 2008; Neff, 1999). This makes global management more efficient and less cost consuming.

\section{High PBG Vs Low PBG Brands}

In this research study the brand which is perceived more available globally and is available all across the world is a global brand more a brand is perceived global by a consumer, it has high $\mathrm{PBG}$, therefore in the concerned research study the global brands are represented as High PBG brands and local brands are represented as Low PBG brands those which are not available across the world but 
they have their presence at domestic or national level in one country or region.

\section{The Emergence of $P B G$}

Regarding the definition and measurement of global brands, there are two main schools in literature. The first school defines global brands as the brands can be found under the same name in multiple countries with similar and coordinated marketing strategies (Branch, 2001; Levitt, 1983; Yip, 1995). In these studies, global brands refer to the extent to which brands adopt $t$ the standardized marketing strategies in various geographical areas.

Recently another school of research in global brands emerged and defined the global brands as the extent to which brands are perceived to be globally available and accepted by consumers (Alden et al.2006; Batra et al.2000; Steenkamp et al.2003). These studies measure global brands in the perspectives of consumers.

Steenkamp et al. (2003) as the representatives of the second school, for the first time proposed the term of perceived brand globalness (PBG), which means the extent to which consumers perceive a brand to be global. For example, if a brand is highly perceived by consumers to be available in other countries outside of their own, the brand has high PBG.

No matter which research stream, one of the most important features of global brand is its global availability and acceptance (Kapferer, 1997; Keller, 2008). The distinctiveness between the two schools is the point of view from which the brands are measured to be global.

This research will focus on the consumer responses and feelings. Therefore, I will follow the second stream and measure the brands from consumer views. Literature suggests that the brands with global image are perceived with higher brand value and better quality than local brands, even the objective features are not superior (Kapferer,1997; Shocker et al.1994). Batra et al. (2000) tested consumer attitudes toward local and non-local brands in India. In their study, non-local brands refer to the brands which are not only consumed by local customers but also by customers abroad. In other words, the non-local brands are available in multiple markets. Furthermore, Batra et al. (2000) found that consumers in developing country have more positive attitudes toward non-local brands than local brands for the scarcity of the non-local brands. This is explained by the relatively less affluent sources in developing countries, where owning a global brand is a sign of high social status.

However, the effects of global brands on consumer attitudes do not only exist in developing countries. Consumers believe the high brand quality as an essential feature for a brand being accepted globally. Steenkamp et al. (2003) tested the effects of PBG in consumers from Korea and US. They proposed the pathways through which PBG creates brand value. Their study found that PBG positively influences the perceived brand quality and brand prestige and then through the two pathways positively influence the purchase likelihood. The effects of PBG exist in both Korean and US consumers.

\section{High Involvement Vs Low Involvement Products}

As seen, many factors influence a consumer's behavior. Depending on a consumer's experience and knowledge, some consumers may be able to make quick purchase decisions and other consumers may need to get information and be more involved in the decision process before making a purchase. The level of involvement reflects how personally important or interested you are in consuming a product and how much information you need to make a decision. The level of involvement in buying decisions may be considered a continuum from decisions that are fairly routine (consumers are not very involved) to decisions that require extensive thought and a high level of involvement. Whether a decision is low, high, or limited, involvement varies by consumer, not by product, although some products such as purchasing a house typically require a highinvolvement for all consumers. Consumers with no experience purchasing a product may have more involvement than someone who is replacing a product.

Consumers often engage in routine response behavior when they make low-involvement decisions - that is, they make automatic purchase decisions based on limited information or information they have gathered in the past. Consumers buy either products or services. While making such purchases, consumers display high or low involvement. High-involvement products are those that represents the consumer's personality, status and justifying lifestyle; for example, buying a home theatre, premium watches, jewelry (diamond and gold), branded apparel, hair color (L’Oréal/Revlon) and sportswear apparel. In contrast, lowinvolvement products are those that reflect routine purchase decisions; for example, buying a candy or an ice cream, hair comb, bathing soap, body deo/spray.

\section{The Moderating Role of CET}

On the contrary of global product preference, consumer ethnocentrism (CET) is a bias of home country product preference (Shimp and Sharma, 1987). Although CET bias is confused with Country of origin (COO) bias, they are distinct and independent concepts. Herche (1992) conducted a study to explain the difference between CET bias and COO bias. For example, a US customer may prefer the French wine because of the COO bias and still not buy it due to the CET bias. Therefore, CET is a kind of general tendency of home country made products preference.

Previous research has documented the enhanced appeal of global brands among certain segments, such as teenagers and businesspeople (Hassan and Katsanis, 1994; Walker, 1996). In this study, I examine the moderating role of CET. 
CET is defined as 'the beliefs held by consumers about the appropriateness, indeed morality, of purchasing foreignmade products' (Shimp and Sharma, 1987). Ethnocentric consumers take pride in their country's brands, symbols, and culture. They are less open to foreign cultures, and are less cosmopolitan. CET is closely linked to economic nationalism (Baughn and Yaprak, 1996). In the thinking underlying economic national-ism, local brands provide a link between the national economy and individual wellbeing. Global brands may be viewed suspiciously as a threat to national economic prosperity. In the mind of ethnocentric consumers, global brands pose not only an economic but also a cultural threat. Lower levels of cosmopolitanism and openness to foreign cultures further contribute to negative evaluations of global brands by more ethnocentric consumers. Ethnocentric consumers may even be willing to sacrifice 'objective' gain (higher quality, lower price, etc.) to enjoy the psychological benefit of avoiding contact with the out-group (i.e., the global culture) by purchasing local brands (Baughn and Yaprak, 1996). On the other hand, consumers low on CET are more cosmopolitan in outlook and have a higher degree of cultural openness (Baughn and Yaprak, 1996).

Furthermore, the CET is heavily related to the economic development status of the country. For instance, studies found that people in developed countries always have stronger preference of the home country made products than people from developing countries. Therefore, literature reported different results regarding the moderating role of CET on product evaluations. Batra et al. (2000) reported no moderating effect of CET was found in the relationship between brand non localness and brand attitude. Steenkmap et al. (2003) found that CET will moderate the effects of the PBG on brand purchase likelihood. These studies were conducted in different countries. Batra's study tested the effects of CET in Indian consumers. However, Steenkamp et al.'s study was conducted in consumers from US and Korea, which are much more developed than India. The difference between the consumers from developed and developing countries per se may cause the different findings in the moderating role of CET. In this thesis, Indian consumer responses will be tested. Since India is a developing country, the moderating role of CET in the relationship between brand failure and consumer responses may be not supported.

Steenkamp et al. modified the original CETSCALE to a four items scale which was found have the as high reliability as the original one. Since this research is also mainly testing the effects of PBG on consumer responses to brand failures, which is quite similar concept to what was tested in Steenkamp's study, the four items are adopted in the CETSCALE to be used in this research as well.

\section{Hypothesis}

In view of the fact that global brands are perceived better and superior to local brands, the failure happens to the global brand is more likely to be thought as accidental or incidental or something beyond the control of the company management. Accordingly, it is proposed that, when a brand which is highly perceived as a global one encounters a failure accidently, consumers should be more likely to attribute the failure to other external reasons rather than the brand itself because of the high perceived quality and prestige of global brand. The consumer treats the failure as occasionally happened incident to a brand which is perceived as a high PBG brand and vice-versa to a low PBG brand. Considering this Hypothesis 1 (H1) is proposed as below:

\section{H1: Considering consumer response towards brand failures, Consumers are less dissatisfied with the brands with high PBG Vs low PBG brands.}

The brand presence all over the world outlets are global brands. Global brands are known as globally available which is attributed by the consumers to be the indication of its high quality (Kapferer, 1997; Keller, 2008). Empirical test supports the positive relationship between PBG and perceived brand quality (Steenkamp et al.2003). Literature suggests that consumer preference for brands with global image over local ones is on higher preference even when the real quality of the global brands is not objectively superior (Kapferer, 1997; Shocker et al.1994). For this reason, when there is a brand failure the high PBG will serve as a buffer to moderate the decline of the perceived brand quality. The perceived brand quality of the high PBG brands is higher than low PBG brands after brand failures take place or ensued. Considering the aforementioned facts hypothesis 2 (H2) is proposed as below:

H2: Considering consumer response towards brand failures, Consumers have higher perception for the quality of brands with high PBG Vs Low PBG brands.

In a brand failure context, dissatisfied consumers are very likely to engage in further behavioral intentions. In literature, the commonly agreed behavioral intentions are negative word of mouth (WOM) and exit (in purchase context should be not to purchase again) (Cronin et al., 2000; Singh, 1988; Zeithaml et al., 1996). All these complaint behavioral intentions are positively related to dissatisfaction and negatively related to consumer quality perception. It is not hard to understand that the more a customer dissatisfied with the brand, the lower quality perception they hold on it and the more likely they are to transmit the negative WOM or decide to not purchase the brand again. WOM transmitting and purchase decision making are both the behavioral intentions following the attitudinal intentions, customer satisfaction and quality perception. Therefore, If the above two hypotheses are 
supported, for the brands with higher level of PBG consumers are less likely to transmit negative WOM and less likely to not purchase it again. Considering this fact hypothesis 3 is proposed:

H3: Considering consumer response towards brand failures, Consumers are restraint to convey negative word of mouth (WOM) for brands with High PBG than low PBG brands.

H4: Considering consumer response towards brand failures, Consumers repurchase intentions are higher for brands with high PBG than low PBG brands.

As found in Steenkamp et al.'s study that the effects of PBG will be moderated by CET. The more ethnocentric consumers the less they prefer the high PBG brand to low PBG brand. When encountering failures, the ethnocentric consumers will blame the high PBG brand more severely. This is consistent with their prior belief that buying high PBG brand is a threat to home country's economy. In this case, the more ethnocentric consumers will respond more negatively to the brand failures. Considering this Hypothesis -H5 is proposed, stating that the effects of the PBG on consumer responses to brand failures will be moderated by CET.

H5: Considering consumer response towards brand failures the impact of $P B G$ will be weaker for more ethnocentric consumers.

People have tendency to attribute the failures differently when happening in case of global and local brands perceived as High PBG and Low PBG brands respectively.

If the failure happens to a brand with higher perceived prestige, which seldom frustrates users, consumers may be more likely to attribute the failure to some other reasons out of control of the brand per se. Because of the perceived usually high quality or good performance of the global brands, the cause of the failure being the accidental case is more rational than the cause of the failure being the poor quality of the brand. If the quality of the high PBG brand if poor, there should be no reason for customers all over the world to accept and buy the product.

When consumers experience the brand failures, they firstly attribute the reason of the failure then take different reactions based on the attributed results. Compared with low PBG brand, consumers are more likely to believe the reason of the failure happening to the high $\mathrm{PBG}$ as accidental, out of control and not very likely to happen again. Once the cause of the failure is believed to be an external reason, the brand per se will be blamed less.

Therefore, based on the attribution results, consumer responses to brand failures of high $\mathrm{PBG}$ brand is less negatively than low PBG brand. On the ground of the above logic, it is proposed that consumer responses to brand failures will be partially mediated by consumer attribution results.

H6: Considering consumer response towards brand failures the impact of $P B G$ will be partially mediated by consumer attribution results of the failure.

\section{Research Methodology}

A structured questionnaire was prepared and presented to the respondents and related questions were asked. Questionnaires mainly contained close-ended questions and a few open-ended questions, to identify the reasons for customer satisfaction and their dissatisfaction.

Under the secondary data, the company's annual reports, brochures, pamphlets, newspapers, journals and internet were taken into consideration. Women of age group 25-40 years from north Indian cities of New Delhi and Jaipur were targeted in this research study as they form the most important consumer segment of fashion and lifestyle products.

\section{Research Design}

The concerned research consists of mainly two studies and two preliminary tests. In the research, Study 1 is executed basically to investigate and to test consumer responses towards brand failures of fictitious brands (untrue brands). Since there are many original differences between the real brands, such as brand familiarity and brand equity, the effects of Perceived Brand Globalness on consumer responses to brand failures of fictitious brands in an assumed scenario presented to respondents (consumers) are easier to test without interruption or presence of those confounding variables. Therefore, the purpose of Study 1 is to test the existence of the consequences of PBG effects on consumer responses and ensure that the effects are not caused by other variables. To generalize the research results to the real market and the real brands actually present in the market, Study 2 is designed to examine consumer responses to brand failures of established brands. In Study 2, all Confounding variables will be carefully controlled to ensure the validity of the experimental results.

Pretest 1 is conducted to verify and validate the general direction of the hypotheses as proposed; it confirms the appropriate product categories to test in later studies and finds out the problems in the construct of the questionnaires for more refinement and improvisation. Pretest 2 asks respondents to evaluate several selected brands and finds out the target established brands with similar attributes and characteristics. The established brands of the real market that share common attributes found in Pretest 2 are then be used as the target brands in Study 2. The purpose of Pretest 2 is to control the possible cofounding variables for the real established brands of the market, such as brand familiarity and brand equity. 


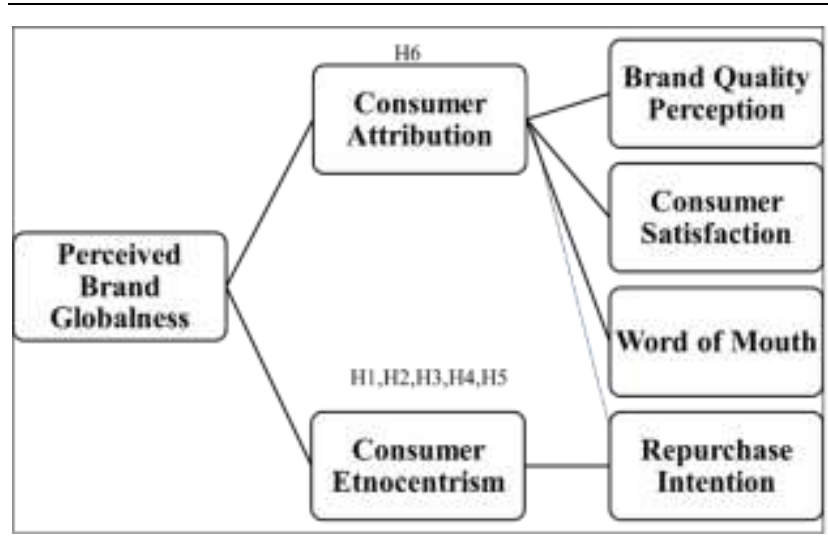

Fig.1: Theoretical Model, Source: Author.

\section{Instrument}

The instrument used is a questionnaire construct with maximum 22 items to be evaluated on a 7 point Likert scale for each statement (Table 1).

\section{Measurement Scales}

All scales used in this study are well developed in literature and have high reliability and validity. Only some minor changes were conducted to the scales to better suit the research topic and respondents of this study.

The scales adopted in the research include:

1. Brand familiarity scale (Steenkamp et al., 2003).

2. Brand Equity scale (Keller and Aaker, 1992).

3. Brand quality perception scale (Steenkamp et al., 2003).

4. Perceived brand globalness scale (Batra et al., 2000; Steenkamp et al., 2003).

5. Customer dissatisfaction scale (Oliver, 1997 Oliver, 1999; Roem and Brady, 2007).

6. Negative WOM scale (Chan and Wan ,2008),

7. Customer purchase intention scale (Dodds et al., 1991; Steenkamp et al., 2003).

8. CETSCALE (Shimp and Sharma, 1987; Steenkamp et al., 2003).

\section{Questionnaire Development}

The questionnaire has been developed in such a way so as to serve the purpose and objectives of the study. The questionnaire for the consumers has been divided into two sections- Technical Data (i.e. subject related data) and Demographical Data. The questionnaire construct of technical questions in the survey questionnaire are structured, with multiple-choice questions, all items framed by using Likert 7-point scale.

\section{Reliability and Internal Consistency of Questionnaire}

The consumer survey questionnaire has been evaluated through testing of reliability and internal consistency, using SPSS. Cronbach's Alpha is used as a measure of internal consistency, i.e. do all the items within the instrument measure the same thing. The closer the Alpha value is towards 1.00 , the greater the internal consistency of items in the instruments being assessed. The formula for determining Alpha makes use of the number of items in the scale (k) and the average correlation between pairs of items. The Cronbach's Alpha for the questionnaire worked out to 0.85 , which is very close to 1 . Hence, the questionnaire is reliable and internally consistent.

The questionnaire from the consumer's point of view consisted of 31 questions, out of which 4 questions are related to CET, and 5 questions are related to Demographical aspects. The balance 22 questions are technical questions, using the Likert 7 point scale and dichotomous scales. The questions are framed in such a manner so as to address the research objectives.

\section{Sample Selection, Survey and Data Collection}

In this research study, the total sample size taken is $\mathrm{N}=200$, with differing size in both the pretests and study 1 and study 2 , which is at $95 \%$ Confidence Level, at $5 \%$ margin of error and $50 \%$ response distribution, to make the sample as representative as possible. As stimuli, the present study has considered twelve well-known brands those who have extended to various products. The twelve well-known brands have been selected from the category of Women lifestyle and fashion, that includes Maybelline lip balm and Himalaya lip balm; Titan and Rado watch; D'dmas and Tanishq jewelry; Zara and Allen Solly (apparel); VLCC and Lakme beauty and wellness services; L'Oreal and Streax hair color. Out of twelve target brands one pair of apparel brand Zara and Allen Solly has been selected as global and local brands as final target brands to be evaluated in the final study 2 .

Survey includes questionnaire, which is online questionnaire and hard copy distribution at various public places like restaurants, malls and cinema halls, Food courts and public parks.

Table 1: 7 point Likert scale used for evaluation.

\begin{tabular}{|l|l|l|l|l|l|l|}
\hline Disagree strongly & Disagree & Disagree slightly & Neutral & Agree slightly & Agree & Agree strongly \\
\hline 1 & 2 & 3 & 4 & 5 & 6 & 7 \\
\hline
\end{tabular}




\section{Covariates}

Three sets of covariates were identified initially. First, brand familiarity was identified as a covariate since we started from pretest 1 and pretest 2 that included a focus group interview to control the factor Brand Familiarity; i.e. brand is familiar to customer to what extent. Brand familiarity is included because previous research suggests that it may have an important impact on perceived brand quality, brand prestige, WOM and re-purchase likelihood, whether or not a brand is perceived as global (Keller, 2008). Second, Brand Equity in pretest 2 did selected one target brand to be evaluated in the final study 2 out of the four pairs of global and local brands. Pretest 2 measures similar Brand Equity for apparel brand ZARA (Global) and Allen Solly (Local) that shared almost similar brand equity and In final study 2 Brand Equity as a covariate is included to control for the possibility that a certain global brand may attain higher satisfaction, prestige, quality, and/or purchase likelihood because it comes from a particular foreign country, rather than because it is global. Finally, we created and add brand dummies for global and local brands which were created to the analyses to control for unobserved, brand-specific effects Controlling for all these variables provides a stronger test of our hypotheses.

\section{Reliability Test Final Study-Study 2}

The reliability test results indicate that all measurement scales obtain a satisfactory Cronbach's alpha value $(>0.70)$. Brand equity scale is consisted of 4 items, after deleting the first item the Cronbach's alpha value reaches 0.79 . The results of reliability of all measurement scales of Study 2 are showed in Table 2.

In Study 1, the reliability of PBG scale doesn't meet the commonly agreed minimum requirement, $\alpha=0.70$. I infer that it is due to the target brands in Study 1 are fictitious brands.
Respondents may have difficulties to answer the questions about "whether the brand is only sold in India based solely on the description of the scenario. Respondents may be not certain about the available region of the fictitious brands, since they never heard of the brand in their daily life. In Study 2, the PBG scale is highly reliable with $\alpha=0.79$. Therefore, all scales adopted in Study 2 are reliable.

The relationship between the variables in the context of failure present was investigated using Pearson productmoment correlation coefficient. Preliminary analyses were performed to ensure no violation of the assumptions of normality, linearity and homoscedasticity. There is a strong, positive correlation between the variables.

\section{Results}

The concerned research in the final Study 2 is targeted to established brands from the real market scenario examining the hypotheses to generalize the research studies. Brand equity was found to have great impacts to consumer responses to failures (Hui, Michael K. and Zhou, 2003; Roehm and Brady, 2007). To control the confounding effect of brand equity on consumer responses, Pretest 2 has been conducted mainly to find out the established brands with similar brand equities as the target brands to test in Study 2 . Study 2 evaluated established apparel brands global and local that shared similar Brand Equity. Study 2 further tested the PBG effects on consumer responses in the context of established brands of Apparel (ZARA and Allen Solly).

ZARA and Allen Solly were confirmed in Pretest 2 to serve as the established apparel brands to be evaluated in Study 2 . There are no significant differences in the scores of brand familiarity between ZARA ( $\mathrm{M}=2.185, \mathrm{SD}=1.12)$ and Allen Solly $(\mathrm{M}=3.605, \mathrm{SD}=1.79)$, also in the scores of brand equity between ZARA (M=5.17, $\mathrm{SD}=1.01)$ and Allen Solly $(\mathrm{M}=5.08, \mathrm{SD}=1.41)$.

Table 2: Reliability Test of Study 2 Items.

\begin{tabular}{|l|l|l|l|}
\hline Scales & Cronbach's Alpha & No. of Items & Items Deleted \\
\hline Perceived brand globalness & 0.74 & 2 & None \\
\hline Customer satisfaction & 0.92 & 3 & None \\
\hline Quality perception & 0.89 & 2 & None \\
\hline Re-purchase intention & 0.95 & 2 & None \\
\hline Word-of-mouth & 0.93 & 2 & None \\
\hline Attribution & 0.88 & 4 & None \\
\hline Consumer ethnocentrism & 0.81 & 4 & None \\
\hline Brand equity & 0.79 & 4 & None \\
\hline Source: Author & & & \\
\hline
\end{tabular}


An independent samples T-test was conducted to compare the means of PBG between global and local brands. The means of failure present and failure absent were also compared with the same method. For PBG manipulation, there is significant difference in scores for global brand $(\mathrm{M}=4.00, \mathrm{SD}=0.5180)$ and local brand $[\mathrm{M}=2.25, \mathrm{SD}=0.62$; $\mathrm{t}(120)=10.99, \mathrm{p}<0.001]$. For brand failure manipulation, significant difference in scores for Failure present $(M=3.59$, $\mathrm{SD}=1.02)$ and failure absent $[\mathrm{M}=5.01, \mathrm{SD}=0.77$; $\mathrm{t}(120)=-$ $9.15, \mathrm{p}<0.001]$ scenarios is also found.

\section{Test of Hypothesis}

A commonly well-established procedure is combining the construct items on Likert-scales into summated ratings or average summated scores. The new transformed composite variable is comparable in scaling to the original scale (Hair et al., 2007). This approach, typically leads to precise structural estimates, provided the measures are unidimensional (Bandalos, 2002) as is the case in this study of brand failures and consumer responses. To validate the hypotheses and estimate the structural relations between the constructs the items were averaged for each scale to obtain composite scale. The mean and standard deviation of the averaged items are reported in Table 3.

To verify the hypothesis concerning the relationship between perceived brand globalness and consumers' purchase intention a path model was designed. Given the sample size $(\mathrm{n}=200)$ and degrees of freedom $(1)$, we found a significant chi-square $\left(x^{2}=3.981\right)$ and fit indexes indicated overall adequate fit to the data, as evidenced by the goodness-of-fit index (GFI) of 0.901, the Tucker Lewis index (TLI) of 0.930, the comparative fit index (CFI) of 0.924 , were all over the 0.90 threshold proposed by ( $\mathrm{Hu}$ and Bentler, 1999). Furthermore, the root mean square error of approximation (RMSEA) is .083 (above the 0.08 threshold proposed by Browne and Cudeck (1992).

Table 4 shows the value of the standardized regression estimate $(0.547,0.970)$ from perceived brand globalness to perceived brand quality is significant $(\mathrm{p}<0.001)$. This supports $\mathrm{H} 2$, showing that from the perspective of the consumers, global brands have high PBG and bear very high quality. This finding is in line with previous research. For international and global brands, research demonstrates that perceived brand globalness could create consumers' perception of "brand superiority" (Kapferer, 1992; Steenkamp et al., 2003). Perceived brand globalness is positively associated with Customer purchase intention ( standardized regression estimate $=(0.541,0.272)$ which is significant $(\mathrm{p}<0.001)$. This supports H4. In addition to quality, international and global brands have been associated with high prestige or status (Batra et al., 2000). Recent empirical studies have demonstrated that "prestige is the second factor driving global brand preference" (Schuiling and Kapferer, 2004; Steenkamp et al., 2003). The standardized regression estimate $(0.085$ - Zara) between perceived brand globalness and consumers' satisfaction was not significant. This does not support $\mathrm{H} 1$ fully and shows that the relationship between brand globalness and consumer satisfaction is mediated by quality and prestige perceptions. The relationship between perceived brand globalness and perceived brand quality was found to be the strongest, supporting $\mathrm{H} 2$. Research also confirms that "quality is among the most important factors that drive consumer preference for global brands" (Holt et al., 2004; Schuiling and Kapferer, 2004; Steenkamp et al., 2003).

In the research study, firstly a univariate linear regression was run to investigate the linear relationship between PBG and consumer attribution under the brand failure circumstance. The overall model explains 12.64 percent of the variance. The ANOVA table indicates that the model as a whole is significant (Table 6, 7). The Coefficients table reveals that consumer attribution is negatively correlated to PBG. That means the more a brand is perceived as a global one the less likely consumers will attribute the failure to the brand.

Table 3: Means and Standard deviations of key constructs in failure present and absent scenarios for Global Vs Local brand.

\begin{tabular}{|l|l|l|l|l|}
\hline & \multicolumn{2}{|c|}{ Failure present } & \multicolumn{2}{c|}{ Failure absent } \\
\hline & Global Brand & Local Brand & Global Brand & Local Brand \\
\hline & ZARA & Allen Solly & ZARA & Allen Solly \\
\hline Customer satisfaction & $2.62(1.26)$ & $2.60(0.97)$ & $2.69(0.90)$ & $2.60(1.23)$ \\
\hline Quality perception & $2.55(1.25)$ & $2.69(1.51)$ & $2.97(1.34)$ & $2.81(1.42)$ \\
\hline Word-of-mouth & $3.15(0.72)$ & $2.90(0.72)$ & $3.20(1.19)$ & $2.93(1.41)$ \\
\hline Re-purchase intention & $2.67(1.43)$ & $2.77(1.31)$ & $2.96(1.35)$ & $2.89(1.61)$ \\
\hline N & $\mathbf{1 5 0}$ & $\mathbf{1 5 0}$ & $\mathbf{1 5 0}$ & $\mathbf{1 5 0}$ \\
\hline Source: Author & & & &
\end{tabular}


Table 4: The standardized regression estimates that show the relationship between Perceived brand globalness and different constructs in the model.

\begin{tabular}{|c|c|c|c|c|c|c|}
\hline Source & Dependent Variable & $\begin{array}{l}\text { Type III Sum } \\
\text { of Squares }\end{array}$ & df & $\begin{array}{l}\text { Mean } \\
\text { Square }\end{array}$ & $\mathbf{F}$ & Sig. \\
\hline \multirow{10}{*}{$\begin{array}{l}\text { Perceived } \\
\text { Brand } \\
\text { Globalness } \\
\text { ZARA }\end{array}$} & Customer satisfaction ZARA & 1.282 & 2 & .641 & 2.604 & .085 \\
\hline & Brand quality ZARA & 1.505 & 2 & .753 & .611 & .547 \\
\hline & Customer repurchase intention ZARA & 1.194 & 2 & .597 & .623 & .541 \\
\hline & Word of mouth ZARA & .269 & 2 & .135 & 1.870 & .166 \\
\hline & Customer Attribution ZARA & .159 & 2 & .079 & .418 & .661 \\
\hline & Customer satisfaction AllenSolly & .245 & 2 & .123 & .417 & .661 \\
\hline & Brand quality AllenSolly & .006 & 2 & .003 & .014 & .987 \\
\hline & Customer repurchase Intention AllenSolly & .969 & 2 & .485 & 1.340 & .272 \\
\hline & Word of mouth AllenSolly & .101 & 2 & .051 & .235 & .791 \\
\hline & Customer Attribution Allensolly & .084 & 2 & .042 & .308 & .736 \\
\hline \multirow{11}{*}{$\begin{array}{l}\text { Perceived } \\
\text { Brand } \\
\text { Globalness } \\
\text { Allen Solly }\end{array}$} & Customer satisfaction ZARA & .746 & 5 & .149 & .606 & .695 \\
\hline & Brand quality ZARA & 1.750 & 5 & .350 & .284 & .919 \\
\hline & Customer repurchase intention ZARA & 2.367 & 5 & .473 & .494 & .779 \\
\hline & Word of mouth ZARA & .243 & 5 & .049 & .676 & .644 \\
\hline & Customer Attribution ZARA & .668 & 5 & .134 & .705 & .623 \\
\hline & Customer satisfaction AllenSolly & .536 & 5 & .107 & .365 & .870 \\
\hline & Brand quality AllenSolly & .180 & 5 & .036 & .176 & .970 \\
\hline & Customer repurchase Intention AllenSolly & 2.189 & 5 & .438 & 1.211 & .320 \\
\hline & Word of mouth AllenSolly & 1.515 & 5 & .303 & 1.408 & .240 \\
\hline & Customer Attribution Allensolly & .518 & 5 & .104 & .763 & .581 \\
\hline & Customer Attribution Allensolly & 1294.063 & 52 & & & \\
\hline
\end{tabular}

a. R Squared $=.912$ (Adjusted R Squared $=.896)$

c. $\mathrm{R}$ Squared $=.936$ (Adjusted R Squared $=.924)$

d. R Squared $=.997$ (Adjusted R Squared $=.996)$

f. $\mathrm{R}$ Squared $=.989$ (Adjusted R Squared $=.987$ )

g. R Squared $=.966$ (Adjusted R Squared $=.960)$

h. R Squared $=.970$ (Adjusted R Squared $=.965)$

i. R Squared $=.992$ (Adjusted R Squared $=.991)$

j. R Squared $=.995$ (Adjusted R Squared $=.995)$

Table 5: Tests of Between-Subjects Effects

\begin{tabular}{|l|l|l|l|l|l|l|}
\hline \multicolumn{2}{|l|}{ Source } & Type III Sum of Squares & df & Mean Square & F & Sig. \\
\hline \multirow{2}{*}{ Perceived Brand Globalness ZARA } & Hypothesis & 3.839 & 2 & 1.920 & 1.640 & .199 \\
\cline { 2 - 7 } & Error & 131.101 & 112 & $1.171^{\mathrm{a}}$ & & \\
\hline \multirow{2}{*}{ Customer Attribution ZARA } & Hypothesis & 24.416 & 5 & 4.883 & 4.172 & .002 \\
\cline { 2 - 7 } & Error & 131.101 & 112 & $1.171^{\mathrm{a}}$ & & \\
\hline
\end{tabular}

Source: Author. Dependent Variable: Brand quality ZARA 
Table 6: ANOVA- ZARA.

\begin{tabular}{|c|c|c|c|c|c|c|}
\hline & & Sum of Squares & Df & Mean Square & $\mathrm{F}$ & Sig. \\
\hline $\begin{array}{l}\text { Customer } \\
\text { satisfaction } \\
\text { ZARA }\end{array}$ & $\begin{array}{l}\text { Between Groups } \\
\text { Within Groups } \\
\text { Total }\end{array}$ & $\begin{array}{l}4.028 \\
27.408 \\
31.436\end{array}$ & $\begin{array}{l}2 \\
117 \\
119\end{array}$ & $\begin{array}{l}2.014 \\
.234\end{array}$ & 8.596 & .000 \\
\hline $\begin{array}{l}\text { Brand quality } \\
\text { ZARA }\end{array}$ & $\begin{array}{l}\text { Between Groups } \\
\text { Within Groups } \\
\text { Total }\end{array}$ & $\begin{array}{l}4.382 \\
155.516 \\
159.898\end{array}$ & $\begin{array}{l}2 \\
117 \\
119\end{array}$ & $\begin{array}{l}2.191 \\
1.329\end{array}$ & 1.648 & .197 \\
\hline WOMZARA & $\begin{array}{l}\text { Between Groups } \\
\text { Within Groups } \\
\text { Total }\end{array}$ & $\begin{array}{l}1.003 \\
8.728 \\
9.731\end{array}$ & $\begin{array}{l}2 \\
117 \\
119\end{array}$ & $\begin{array}{l}.502 \\
.075\end{array}$ & 6.725 & .002 \\
\hline CPIZARA & $\begin{array}{l}\text { Between Groups } \\
\text { Within Groups } \\
\text { Total }\end{array}$ & $\begin{array}{l}5.119 \\
118.873 \\
123.992\end{array}$ & $\begin{array}{l}2 \\
117 \\
119\end{array}$ & $\begin{array}{l}2.560 \\
1.016\end{array}$ & 2.519 & .085 \\
\hline CAZARA & $\begin{array}{l}\text { Between Groups } \\
\text { Within Groups } \\
\text { Total }\end{array}$ & $\begin{array}{l}.240 \\
21.842 \\
22.083\end{array}$ & $\begin{array}{l}2 \\
117 \\
119\end{array}$ & $\begin{array}{l}.120 \\
.187\end{array}$ & .644 & .527 \\
\hline
\end{tabular}

Source: Author.

Table 7: ANOVA- Allen Solly

\begin{tabular}{|c|c|c|c|c|c|c|}
\hline & & Sum of Squares & $\mathrm{df}$ & Mean Square & $\mathrm{F}$ & Sig. \\
\hline CSALSL & $\begin{array}{l}\text { Between Groups } \\
\text { Within Groups } \\
\text { Total }\end{array}$ & $\begin{array}{l}1.417 \\
28.685 \\
30.103\end{array}$ & $\begin{array}{l}5 \\
114 \\
119\end{array}$ & $\begin{array}{l}.283 \\
.252\end{array}$ & 1.127 & .350 \\
\hline BQALSL & $\begin{array}{l}\text { Between Groups } \\
\text { Within Groups } \\
\text { Total }\end{array}$ & $\begin{array}{l}.529 \\
19.869 \\
20.398\end{array}$ & $\begin{array}{l}5 \\
114 \\
119\end{array}$ & $\begin{array}{l}.106 \\
.174\end{array}$ & .607 & .695 \\
\hline WOMALSL & $\begin{array}{l}\text { Between Groups } \\
\text { Within Groups } \\
\text { Total }\end{array}$ & $\begin{array}{l}2.755 \\
22.837 \\
25.592 \\
\end{array}$ & $\begin{array}{l}5 \\
114 \\
119 \\
\end{array}$ & $\begin{array}{l}.551 \\
.200\end{array}$ & 2.750 & .022 \\
\hline CPIALSL & $\begin{array}{l}\text { Between Groups } \\
\text { Within Groups } \\
\text { Total }\end{array}$ & $\begin{array}{l}3.277 \\
41.189 \\
44.467 \\
\end{array}$ & $\begin{array}{l}5 \\
114 \\
119 \\
\end{array}$ & $\begin{array}{l}.655 \\
.361\end{array}$ & 1.814 & .116 \\
\hline CAALSL & $\begin{array}{l}\text { Between Groups } \\
\text { Within Groups } \\
\text { Total }\end{array}$ & $\begin{array}{l}1.127 \\
15.318 \\
16.445\end{array}$ & $\begin{array}{l}5 \\
114 \\
119 \\
\end{array}$ & $\begin{array}{l}.225 \\
.134\end{array}$ & 1.678 & .145 \\
\hline BEALSL & $\begin{array}{l}\text { Between Groups } \\
\text { Within Groups } \\
\text { Total }\end{array}$ & $\begin{array}{l}.988 \\
56.911 \\
57.899\end{array}$ & $\begin{array}{l}5 \\
114 \\
119\end{array}$ & $\begin{array}{l}.198 \\
.499\end{array}$ & .396 & .851 \\
\hline
\end{tabular}

Source: Author

A univariate linear regression was tested to detect whether brand quality perception is linearly correlated to PBG and consumer attribution. The ANOVA table indicates that the model as a whole (which includes both independent variables $)$ is significant $[\mathrm{F}(2,112)=1.640, \mathrm{p}<0.01]$. Global brands. However, the coefficients table reveals that only PBG makes a statistically significant contribution $(\mathrm{p}<0.01)$. Consumer attribution is not significantly 
correlated to quality perception. Same results are got from the test between consumers re-purchase intention and PBG and consumer attribution. The model as a whole (which includes both independent variables) is significant [F (2, $112)=4.78, p<0.01]$. However, consumer Attribution does not make a significant contribution to the variance of consumers re-purchases intention after brand failures.

Same method was used to investigate the mediating role of consumer attribution in the relationship between PBG and customer satisfaction, as well as the relationship between PBG and WOM.

Results indicate that consumer attribution has a significant contribution to both customer satisfaction $[\mathrm{F}(5,119)=$ $1.27, \mathrm{P}<0.01]$ and $\operatorname{WOM}[\mathrm{F}(1,119)=2.750, \mathrm{P}<0.01]$.

Before controlling the effect of attribution, PBG was found to significantly influence consumer responses in all four attitudinal and behavioral aspects. However, after controlling the effect of attribution, the significant level of PBG effect on customer satisfaction and word-of-mouth is obviously decreased figures can be checked from the above table (customer satisfaction, word-of-mouth). This indicates that the effect of PBG on customer satisfaction and wordof-mouth is partially mediated by attribution. Besides the change in $\mathrm{p}$ values the non-standardized beta coefficients values drop sharply for customer satisfaction and word-ofmouth. The above statistics reveal the partial mediation effect of attribution on the relationship between PBG and customer satisfaction as well as the word-of-mouth from the decrease in both values of $\mathrm{p}$ and non-standardized beta coefficients.

Although the significant level of PBG effect on re-purchase intention slightly drops after controlling the effect of attribution, the 0.01 difference between $p$ values does not actually mean the statistical change. The decrease of the non-standardized beta coefficients values for the two dependent variables are too slightly to indicate any mediation effects.

Attribution does not make a significant contribution to the variance of consumer's re-purchase intention after brand failures. Same method was used to investigate the mediating role of consumer attribution in the relationship between PBG and customer satisfaction, as well as the relationship between PBG and WOM. Results indicate that consumer attribution has a significant contribution to both customer satisfaction $[\mathrm{F}(5,119)=1.27, \mathrm{P}<0.01]$ and WOM $[\mathrm{F}(1$, $119)=2.750, \mathrm{P}<0.01]$.

Before controlling the effect of attribution, PBG was found to significantly influence consumer responses in all four attitudinal and behavioral aspects. However, after controlling the effect of attribution, the significant level of PBG effect on customer satisfaction and word-of-mouth is obviously decreased figures can be checked from the above table (customer satisfaction, word-of-mouth). This indicates that the effect of PBG on customer satisfaction and wordof-mouth is partially mediated by attribution. Besides the change in $p$ values the non-standardized beta coefficients values drop sharply for customer satisfaction and word-ofmouth. The above statistics reveal the partial mediation effect of attribution on the relationship between PBG and customer satisfaction as well as the word-of-mouth from the decrease in both values of $\mathrm{p}$ and non-standardized beta coefficients.

Although the significant level of PBG effect on re-purchase intention slightly drops after controlling the effect of attribution, the 0.01 difference between $p$ values does not actually mean the statistical change. The decrease of the non-standardized beta coefficients values for the two dependent variables are too slightly to indicate any mediation effects.

The results listed in Table 4-6 reveal all the figures for the partial mediating effect of attribution on the relationship between PBG and customer satisfaction as well as the relationship between PBG and word-of-mouth. No mediating effects of attribution were found on the relationship between PBG and quality perception or the relationship between $\mathrm{PBG}$ and re-purchase intention. Detailed reasons will be discussed in the conclusion part of Study 2 . H6 is partially supported.

\section{Research Limitations and Directions for Future Research}

Although the research study contributes to both the literature and business from several aspects, there are still some limitations.

\section{Customer Ethnocentrism}

CET: The main limitation of sample selection in the research lies in the low level of CET of the respondents. There is no significant difference in the level of CET between the respondents. In addition, the highly educated respondents generally hold open attitude to foreign product/brand. Therefore, the research could not conclude for CET that does not have effects on all Indian consumer respondents based on the results. From the futuristic point of view, researchers can test the moderating effect of CET in the samples with more age and cultural varieties and diversity of population as a sample to get a deeper view into Indian consumer attitudes to global brands.

Second, although the mediating role of consumer attribution is supported in some cases, the reason for why consumers are more likely to attribute the failures happened to low PBG brands as the fault of the brands is worth interesting and further investigation. Future research could probe into the process of attribution and find out the reason behind the cause inference results. Attribution is a more complex response and change behavior and complicated process, and 
will be influence by many internal and external factors. Literature suggests a number of biases existing in the process of attribution. All these are interesting points worth considering and testing in the future research.

Third, only two product types (pretest 1), three fictitious (Study 1) and two established brands were evaluated (Study 2) in the concerned research study. Apparel as tangible product and Beauty and Wellness services as intangible product were evaluated in the study. Product high and low involvement product may have moderating effects on the relationship between PBG and consumer responses. Pretest 1 did not find the significant effects of PBG on consumer responses to the failures of Lip balm. Consumers pay less attention to the brand of a low involvement product Lip balm than Watch. Evaluations on the lip balm, which is a low involvement product, do not differ much between global and local brand when there is a failure. There could be variety of brands category and researchers may test more types of products with different levels of product involvement in the future study to find out the difference between consumer reactions to global and local brand.

Finally, the respondents were more responsive and only reacted to one failure scenario. The severity of the failure could have moderating role in the relationship between consumer responses and brand failures. In addition, the frequencies of failure should be another point worth of considering. For example, generally as a common perception global brand is superior to local brand even in the context of failure. According to expectation theory, the higher expectation consumers have toward the brand the more dissatisfied they feel about the failure. In the research study, the failure scenario was described with medium severity and not commonly happened. However, if the failures are more general and happened commonly, will consumer have the same reaction and responses when the failure happened once, twice or even more times? Future researchers may test consumer responses to different severity of failures. In addition, it is worth investigating the threshold of failure happening frequencies to consumers still respond less negatively to global brands than local brands.

\section{References}

Alden DL, Steenkamp JB, Batra R (2006) Consumer attitudes toward marketplace globalization: Structure, antecedents and consequences. International Journal of Research in Marketing 23(3): 227-239.

Bandalos DL (2002) The effects of item parceling on goodnessof-fit and parameter estimate bias in structural equation modeling. Structural equation modeling 9(1): 78-102.

Batra R, Ramaswamy V, Alden DL, Steenkamp JB, Ramachander $S$ (2000) Effects of brand local and nonlocal origin on consumer attitudes in developing countries. Journal of consumer psychology $\mathbf{9}(2)$ : 83-95.

Batra R, Ramaswamy V, Alden DL, Steenkamp JBE and
Ramachander S (2000) Effects of brand local and nonlocal origin on consumer attitudes in developing countries. Journal of consumer psychology 9(2): 83-95.

Baughn CC and Yaprak A (1996) Economic nationalism: Conceptual and empirical development. Political Psychology 759-778.

Branch S (2001) AC Nielsen gives 43 brands global status. Wall Street Journal 31: B8.

Browne MW and Cudeck R (1993). Alternative ways of assessing model fit. Sage focus editions 154: 136-136.

Chan H and Wan LC (2008) Consumer responses to service failures: a resource preference model of cultural influences. Journal of International Marketing 16(1): 7297.

Cronin JJ, Brady MK and Hult GTM (2000) Assessing the effects of quality, value, and customer satisfaction on consumer behavioral intentions in service environments. Journal of retailing 76(2): 193-218.

Dodds WB, Monroe KB and Grewal D (1991) Effects of price, brand, and store information on buyers' product evaluations. Journal of marketing research 307-319.

Folkes VS and Kotsos B (1986) Buyers' and sellers' explanations for product failure: who done it? The Journal of Marketing 74-80.

Folkes VS (1984) Consumer reactions to product failure: An attributional approach. Journal of consumer research 10(4): 398-409.

Haig M (2005) Brand failures: the truth about the 100 biggest branding mistakes of all time. Kogan Page Publishers.

Hair JF, Money A, Samouel P and Page M (2007) Research Methods for Business, Wiley, Chichester.

Hassan SS and Katsanis LP (1994) Global market segmentation strategies and trends (pp. 47-62). New York: International Business Press.

Herche J (1992) A note on the predictive validity of the CETSCALE. Journal of the Academy of Marketing Science 20(3): 261-264.

Holt DB, Quelch JA and Taylor EL (2004) How global brands compete? Harvard Business Review 82(9): 68-75.

Hu LT and Bentler PM (1998) Fit indices in covariance structure modeling: Sensitivity to under parameterized model misspecification. Psychological methods 3(4): 424.

Hui MK and Zhou L (2003) Country-of-manufacture effects for known brands. European journal of marketing 37(1/2): 133-153.

Kapferer JN (1997) Strategic brand management: creating and sustaining brand equity long term, 2. Auflage, London.

Keller KL and Aaker DA (1992) The effects of sequential introduction of brand extensions. Journal of marketing research 35-50.

Keller KL (2008) Strategic brand management: Building, measuring, and managing brand equity. Upper Saddle River, NJ: Pearson/Prentice Hall.

Levitt T (1983) The Globalization of Markets. Harvard Business Review 61(3): 91-102.

Oliver RL (1997) Emotional expression in the satisfaction response. Satisfaction: A behavioral perspective on the consumer 291-325.

Oliver RL (1999) Whence consumer loyalty?.The Journal of Marketing, 33-44.

Roehm ML and Brady MK (2007) Consumer responses to 
performance failures by high-equity brands. Journal of Consumer Research 34(4): 537-545.

Schuiling I and Kapferer JN (2004) Executive insights: real differences between local and international brands: strategic implications for international marketers. Journal of International Marketing 12(4): 97-112.

Shimp TA and Sharma S (1987) Consumer ethnocentrism: construction and validation of the CETSCALE. Journal of marketing research 280-289.

Shocker AD, Srivastava RK and Ruekert RW (1994) Challenges and opportunities facing brand management: An introduction to the special issue. Journal of marketing research 31(2): 149-158.
Singh J (1988) Consumer complaint intentions and behavior: definitional and taxonomical issues. The journal of Marketing 93-107.

Steenkamp JBE, Batra R and Alden DL (2003) How perceived brand globalness creates brand value. Journal of International Business Studies 34(1): 53-65.

Yip GS (1995) Instructor's Manual: Total Global Strategy: Managing for Worldwide Competitive Advantage. Prentice Hall.

Zeithaml VA, Berry LL and Parasuraman A (1996) The behavioral consequences of service quality. The Journal of Marketing $31-46$. 